\title{
Review of Failure Mechanism and Modification Research of Recycled Aggregate Concrete
}

\author{
Ying Liu 1, a, Peng Peng ${ }^{1,2}$ \\ ${ }^{1}$ Research Institute of Highway, Ministry of Transport, Beijing 100088, China. \\ ${ }^{2}$ China Highway \& Transportation Society, Beijing 100029, China. \\ a424751349@qq.com
}

\begin{abstract}
In this paper, the failure mechanism and modification research of damage performance of recycled aggregate concrete were summarized systematically. The general failure rules of recycled aggregate concrete were summarized according to the failure mode and fracture characteristics of recycled aggregate concrete. Based on the failure mechanism, the modification research ideas of improving the mechanical properties were obtained, and the modification method was proposed. This paper introduced the reinforcement technology of recycled aggregate and summarized the problems that need to be solved for recycled aggregate concrete.
\end{abstract}

Keywords: Recycled aggregate concrete; Damage performance; Fracture characteristics.

\section{Introduction}

With the rapid development of the society and the reconstruction of the infrastructure, the demand for concrete is increasing, and the treatment of a large number of demolished building wastes will bring some harm to the environment. Therefore, this paper put forward the basic idea of recycled aggregate concrete, and hopes to replace partially ordinary concrete with recycled aggregate concrete. It can not only meet the social needs, but also reduce the harm to the environment and realize the recycling of resources, and recycled aggregate concrete research also become the focus of social research nowadays. However, due to the large amount of old adhered mortar in recycled aggregate, it has certain defects in mechanical properties compared with ordinary concrete [1-3].At present, the processing mechanism of recycled aggregate concrete technology is not perfect, and there are many bottlenecks that need to be broken in order to improve various mechanical performance indexes. All of these limit the development of recycled aggregate concrete to a large extent. So far, recycled aggregate concrete has been mostly used in some non-load-bearing components or road surfaces. The study on the damage mechanism and modification method of recycled aggregate concrete are of great significance for improving the destructive of recycled aggregate concrete and strengthen its application in engineering.

According to the related research, it is found that either the tensile failure or the compression failure of the recycled aggregate concrete is manifested by the fracture of the old adhered mortar and the interface transition zone. The initial micro cracks in the process are usually first appeared in the interface transition zone, and then extend to the mortar area. Therefore, the interface transition zone is the weakest link of recycled aggregate concrete, and the main factor causing this phenomenon is the existence of old mortar. To a large extent, the old mortar influences the difference in quantity, distribution and performance of interface transition zone. In recent years, many scholars have done research on recycled aggregate concrete, and have made a series of research achievements in improving the performance of recycled aggregate and the strength of recycled aggregate concrete. This paper will sort out and summarize these achievements in order to further expand and improve the regenerative aggregate concrete damage machine. It provides a reference for the research work of theory and modification. 


\section{Mechanism of Improving Failure Performance of Recycled Aggregate Concrete}

The failure of recycled aggregate concrete block is mainly caused by tensile failure and compression failure.

\subsection{Tensile Failure}

At present, there are not many researches on the tensile failure of recycled aggregate concrete. In terms of its failure form, the failure surface of recycled aggregate concrete is mainly the fracture of mortar. Secondly, the interfacial transition zone between natural aggregate and new mortar or old mortar is damaged, while the fracture of recycled aggregate is relatively less. Existing studies show that the tensile strength of recycled aggregate concrete is related to many factors, such as replacement rate, mix ratio and water-cement ratio. The split tensile test of Tabsh et al.[4] shows that the splitting tensile strength of recycled aggregate concrete is related to the mixing ratio of recycled aggregate concrete, which is generally 10\% 25\% lower than that of ordinary concrete. Ikeda et al.[5-6] found that the tensile strength of recycled aggregate concrete was $6 \% \sim 10 \%$ lower than that of ordinary concrete, Sageo-Crent-sil et al.[7] test show that The ratio between tensile strength and compressive strength of recycled aggregate concrete is slightly higher than that of ordinary concrete, Gupta[8] test find when water-cement ratio is low, the tensile strength of recycled aggregate concrete is lower than normal concrete, and water cement ratio is high, the tensile strength of recycled aggregate concrete is higher than that of ordinary concrete.

\subsection{Compression Failure}

As compression is the main performance of concrete, it is common to study the compressive failure and compressive strength of recycled aggregate concrete. The researches of Jianzhuang Xiao et al,[9] show that the compressive strength of recycled aggregate concrete is closely related to the replacement rate, water-cement ratio and age, etc., and the failure surface of recycled aggregate concrete basically starts from the bond failure between coarse aggregate and hydrogels. Xu-ping $\mathrm{Li}[10]$ research on mechanical performance of recycled aggregate concrete suggests that modulus of elasticity of recycled aggregate concrete is lower than the ordinary concrete and peak strain and brittleness are bigger than the ordinary concrete, and the failure form of prism is longitudinal splitting under uniaxial compression. Xuebing Zhang et al.[11] prove that water-cement ratio have a great influence on compressive strength of recycled aggregate concrete with different mixing ratios. Throughout the existing studies, the compressive failure of recycled aggregate concrete test blocks is mainly caused by oblique cracks, and a few of them are caused by local crushing. Most of the fracture surfaces of recycled aggregate concrete are old mortar fracture and interface transition zone failure, namely interface transition zone between natural aggregate and new mortar or old mortar.

\section{Modification of Recycled Aggregate Concrete}

\subsection{Physical Reinforcement Method}

\subsubsection{Mechanical Grinding}

Existing studies have shown that mechanical grinding can remove the old mortar from the surface of recycled aggregate to a certain extent and effectively improve the performance of recycled aggregate. When Montgomery studied the effect of the amount of recycled aggregate surface mortar on the performance of recycled aggregate concrete, Montgomery[12] used ball grinding method to remove the old mortar from the recycled aggregate surface very well. Dezhan He[13] find that the performance of regenerated aggregates is improved greatly in Japan by vertical eccentric device grinding and horizontal rotary device grinding, and the recovery rate of recycled aggregate after grinding by vertical eccentricity device is up to $67 \%$ compared with original concrete, and reached the standard of Japan about regeneration aggregate performance. 


\subsubsection{Heating Grinding}

Heating grinding is an improved method developed on the basis of original mechanical grinding. Compared with mechanical grinding, it has better effect, but the process is more complicated. After $60 \mathrm{~min}$ heating and 120 min grinding, the surface mortar adhesion rate of regenerated aggregate can be reduced to $0 \% \sim 20 \%$ in relevant factories in Japan, and the water absorption and porosity both decrease significantly and the performance improve significantly. Bru et al.[14] have used the selective heating and grinding method to radiate the waste concrete block by microwave first, and then remove the old mortar from the surface of the aggregate by mechanical grinding, so as to obtain the recycled aggregate with good performance. In addition, Tateyashiki et al.[15-16] have also confirmed through experiments that the heating and grinding method can produce good quality recycled aggregate.

\subsubsection{Particle Shaping}

Particle shaping reinforcement is mainly used to strike out the mortar or cement stone attached to the surface of the aggregate by high speed autoclave and friction of the reclaimed aggregate, remove the prominent edges and corners on the aggregate granule and make it a clean and smooth recycled aggregate, so as to realize to the strengthening of the recycled aggregates. Qiuyi Li[17-18] find, according to the research of aggregate particle shaping, that the performance of regenerated aggregate is improved significantly after the Particle shaping reinforcement, and the performance of some high quality recycled coarse aggregate can even be comparable to that of natural gravel, and the performance of recycled fine aggregate has also been greatly improved. Chongji Zhu et al.[19] find through the particle shaping of aggregate that the concrete made of recycled aggregate after particle shaping had significantly enhanced the anti-permeability and anti-carbonization ability of chloride ions.

\subsubsection{Stirring Process}

Reasonable stirring technology can not only strengthen the regenerated aggregate, but also improve the performance of interface transition zone to a certain extent. The secondary stirring process advocates that on the basis of taking into account the uniform mixing of all materials in the concrete components, by using the amount of material and mixing order to improve the inner structure of concrete and its performance, the main characteristic of secondary stirring process is that it can eliminate the phenomenon of cement particle clumping., so as to make cement hydration more fully, at the same time can effectively improve the high water cement ratio condition of interface transition zone, improve the strength of concrete. Ryu etc.[20-21] through secondary mixing process of the preparation of recycled aggregate concrete study shows that compared with the conventional stirring process, the compressive strength and tensile strength of the recycled aggregate concrete prepared by the secondary stirring process under the same conditions are improved to different degrees, and find that the thickness of the interface transition zone decrease by 38\%. Tam et al.[22] find that the secondary stirring process make the interface transition zone more compact, which can significantly increase the strength of recycled aggregate concrete and reduce its dispersion. Tamura et al.[23] used decompression mixing technology to prepare recycled aggregate concrete, and find that it can increase the compressive strength of concrete by $20 \%$. In addition, Wu Zhao et al.[24-25] have proved that the mixing process can help improve the strength and performance of recycled aggregate concrete through different stirring methods.

\subsubsection{Wet Treatment}

The wet treatment method is mainly to wash the reclaimed aggregate with water, and then to obtain the better quality recycled aggregate by separating the impurities in the recycled aggregate. This treatment method is simple and has certain effect on removing dust from recycled aggregate and enhancing interface adhesion. Jung-mann[26] improve the production process by washing the broken regenerated aggregate with water before screening, and obtaine a good quality regenerated aggregate. Katz[27] find that the effect of such treatment method was not obvious through the study of ultrasonic cleaning of recycled aggregates, and only the weak recycled aggregates of matrix concrete can be 
improved. It is not hard to find that the biggest characteristic of wet treatment compared with other reinforcement methods is its simple operation, can use local materials, moreover, washing away the dust on the surface of the aggregate has certain effect on improving the interface transition zone of recycled aggregate concrete, but the optimization performance of rinsing with water alone is limited, so it needs to be combined with other reinforcing methods.

In conclusion, these physical strengthening methods have achieved certain results in modifying and recycled aggregate, but, some methods may have high requirements on equipment and complicated procedures, while those with simple procedures may not have good enhancement effect. Therefore, how to improve the recycled aggregate processing technology needs further research and discussion.

\subsection{Chemical Method}

\subsubsection{Chemical Immersion}

Different from physical strengthening method, chemical soaking is mainly to improve the pore structure on the surface of recycled aggregate and the enhancement is achieved by enhancing its compactness. Chemical soaking is divided into chemical solution soaking and chemical slurry soaking. Kou et al.[28] find through the research of the recycled aggregate is soaked by polyvinyl alcohol that the apparent density of the regenerated aggregate after modification increase significantly and the water absorption rate decrease significantly. Jianliang Chen et al.[29] use the method of mechanical grinding combined with polyvinyl alcohol immersion to treat the recycled aggregate, and find that the flexibility and compressive strength of the recycled aggregate concrete both improve after treatment. Ning Yang et al.[30] find that the compressive strength of recycled aggregate concrete cube can be increased by $22 \%$ by spraying polyvinyl alcohol solution on the aggregate surface and wrapping in cement. This method is more feasible than other methods. Abbas et al.[31] confirm that concentrated sodium sulfate solution soak recycled aggregates, again with mechanical mixing mortar freezing and thawing, can very good remove old recycled aggregates surface mortar, improve the performance of recycled aggregate. All these are reinforced recycled aggregates by soaking them in a chemical solution, and the effects are different. However, it remains to be further studied whether there is any effect on the durability of recycled aggregate after soaking in chemical solution.

For the reinforcement of recycled aggregate by chemical slurry immersion, Xiaoping Fan et al.[32] find that the compound water-repellent slurry composed of the cement of water-cement ratio 1:1 mixed with inorganic aluminum salt can strengthen the recycled aggregate very well. Ting Du et al.[33] strengthen the recycled aggregate by high-activity superfine mineral and admixture slurry, and find that the performance of the recycled aggregate improve significantly under the immersion of the cement mixed slurry with Kim powder. Katz[34] try to cover the surface of the recycled aggregate with a layer of silica powder particles in order to react with the cement hydration products remaining on the surface of the recycled aggregate so as to form a dense layer on the surface of the aggregate, so the recycled coarse aggregate is strengthened with silica powder solution, and find that the compressive strength of $7 \mathrm{~d}$ and $28 \mathrm{~d}$ increase by $30 \%$ and $15 \%$ respectively, and the early intensity increase more than the later intensity, this indicates that the filling effect of silica powder solution is more dominant than that of volcanic ash.

\subsubsection{Polymer and Carbonization}

In view of some properties of recycled aggregate, the performance of recycled aggregate concrete can be improved by utilizing the filling action of polymer and the change of its flocculation structure by participating in hydration reaction of cement. Many scholars have done relevant studies in this field, but according to the materials they choose, the final results are also different. Ziming Wang et al.[35] through the modification research of recycled fine aggregate by three polymers: styrenebutadiene rubber (SBR), polyacrylate (EVA) and vinyl acetate (PAE) find that the compressive strength of recycled fine aggregate mortar don 't improve after the PAE emulsion treatment, and just the flexural strength of recycled fine aggregate increased significantly. The research of Kou et al.[36] show that the physical performances of recycled aggregates can be improved obviously after 
impregnation with polyvinyl alcohol (PVA), especially the water absorption of recycled aggregates. Spaeth[37] find that using silane polymers, siloxane polymers and silane-silane-siloxane-doped polymers to soak the recycled aggregates can reduce the water absorption of the recycled aggregates, and the amount of reduction is related to the type of polymer. Tsujino et al.[38]have come to a similar conclusion, but it is found that the compressive strength of recycled aggregate concrete was decreased after treatment with silane polymer, it most likely is caused due to the different test methods. In view of the above phenomenon, the pore structure of recycled aggregate is also filled by polymer immersion. Why some of them are effective and some of them are not, to explain this phenomenon we need to study the chemical effects of several materials. Grabiec[39] through biological precipitation generated $\mathrm{CaCO} 3$ crystal, and make it to fill in mortar adhered on the surface of the recycled aggregates in order to increase its compactness, and find that it is effective to improve the strength of recycled aggregate concrete. It is well known that carbonization reduces the alkalinity of concrete and easily causes steel corrosion, but because carbonization changes the hydration products of cement, to some extent, it can make the concrete more compact and harder. Zhang et al.[40] are inspired by this, they use $\mathrm{CO} 2$ to strengthen the treatment of recycled aggregate, and find that can make the recycled aggregates water absorption and crush index decrease obviously, apparent density increased, and it has good effect on improving the strength of recycled aggregate.

\subsection{High Temperature Steaming Pressure and Microwave Heating}

In order to remove the old mortar on the surface of recycled aggregate and enhance the performance of recycled aggregate, high temperature autoclave and microwave heating also have certain effects. Zhenglong Cui et al.[41] through the study find that the effect of high temperature autoclave curing on the recycled aggregate is not satisfactory, and the strength of the recycled aggregate decreased to a certain extent in the later stage, which may be that the high temperature autoclave damaged the aggregate itself. Akbarnezhad et al.[42] have conducted high power microwave $(10 \mathrm{~kW})$ enhancement on the recycled aggregate, which proves that microwave can indeed play a role in removing the surface mortar of the recycled aggregate, but high power instantaneous heating can lead to high temperature of the natural aggregate inside the regenerated aggregate, resulting in high temperature damage of the aggregate itself. Jianzhuang Xiao et al.[43], on the basis of this, put forward the idea of the low power microwave heating to strengthen the recycled aggregates, namely, through the method of microwave heating cycle to remove old mortar adhered to the recycled aggregates so as to improve the quality of recycled aggregates. Compared with the traditional method of wrapping pure water slurry and the method of mechanical grinding, the effect of microwave heating is more obvious. In addition, Jun Dai et al.[44] prove through experiments that the performance of recycled aggregate can be improved significantly by mechanical selection assisted by microwave heating.

\section{Problems to be Solved}

\subsection{Regenerated Aggregate Processing Mechanism}

There is no doubt about the effect of recycled aggregate on the performance of recycled concrete. The most essential difference between recycled aggregate and natural aggregate is the addition of old mortar ingredients. Although there are various methods to strengthen recycled aggregate at present, the final effect is also different. However, these factors aside, because the source of waste concrete is complex, the production and processing of recycled aggregate must be standardized and large-scale, and it can only be processed in factories with corresponding qualifications, and the classification of different strength levels should be made, moreover, no private small factories or workshops are allowed to exist, only in this way can the quality of recycled aggregate be guaranteed. Therefore, it is a prerequisite for the development of recycled aggregate concrete technology to strengthen recycled aggregate. 


\subsection{Numerical Simulation Technology}

The development of a civil engineering technology requires not only effective experimental research, but also reasonable theoretical analysis. As for the application and promotion of the technology of recycled aggregate concrete, it is of great significance to simulate the fine and micro structure of recycled aggregate concrete to understand its macroscopic performances. Although the scholars have put forward various fine micro numerical model, such as lattice model, the stochastic particle model, micro plane model, MH model, the beam particle model and cellular automata model, etc., but these models all have insufficient, It only meet the performance requirements of recycled aggregate concrete in one aspect and are not perfect. Therefore, the technology of numerical simulation is still to be improved.

\subsection{Formation of Application System}

At present, the application of recycled aggregate concrete is still in the stage of test and prudent use, although there have been some demonstration project research, and made the corresponding recycled aggregates and recycled aggregate concrete technical regulations and technical standards, but, considering the dispersion of recycled aggregate concrete, the application of recycled aggregate concrete is still cautious at present. The ultimate purpose of each study is to apply. Therefore, a scientific and effective application system should be established after the research on the damage performance of modified recycled aggregate concrete has achieved certain results to research how to maximize its application and extension in the condition of ensuring the strength of recycled aggregate concrete.

\subsection{Establish a Scientific and Effective Monitoring Mechanism}

The application of recycled aggregate concrete in the engineering, especially in some important applications of bearing component, we should establish scientific and effective monitoring mechanism in order to be able to grasp all the performance indicators under environmental action and stress at anytime and anywhere. For example, as time goes on, how about its surface carbonization, how about internal steel corrosion, Whether the durability of recycled concrete after chemical soaking is affected, and what are the disadvantages compared with ordinary concrete components under the same conditions. After the comprehensive analysis of the information, the performance of the recycled aggregate concrete component will be further improved, which will provide a basis for guiding the engineering application in the future.

\section{Conclusion}

(1) The existing research data show that recycled aggregate concrete has more discretization and more complex interface transition area than ordinary concrete. In order to improve the failure behavior of the modified recycled aggregate concrete, it is necessary to understand its failure mechanism and find different modification measures according to different needs and failure modes.

(2) According to the research background and reality of recycled aggregate concrete, the research system of modified recycled aggregate concrete is proposed, including the research target, research content, destruction mechanism of concrete.

(3) Based on the existing data, this paper puts forward the modified thinking from the damage mechanism to the destructive energy, and summarizes the modification research of recycled aggregate concrete, and points out the problems that need to be solved further to improve the development and application of recycled aggregate concrete.

(4) Whether it is subjected to tensile damage or compressive damage, the recycled aggregate concrete shows the fracture of the old mortar and the destruction of interfacial transition zone, which can be concluded that the interfacial transition zone is the weakest region, therefore, to improve the failure performance of recycled aggregate concrete, the most critical is to strengthen the interface transition zone. 


\section{References}

[1]. OTSUKI N,MIYAZATO S,YODSUDJAI W. Influence of Recycled Aggregate on Interfacial Transition Zone, Strength, Chloride Penetration and Carbonation of Concrete[J]. Journal of Materials in Civil Engineering, 2003, 15(5):443-451.

[2]. TOPCU I B, SENGEL S. Properties of Concretes Produced with Waste Concrete Aggregate [J]. Cement and Concrete Research, 2004, 34(8): 1307-1312.

[3]. LI Juan. Influence of Mortar Adhesive to Recycled Aggregate on Strength of Concrete and Research of Lime-fly Ash Stabilized Recycle Aggregate [D].Master, Hohai University, China 2005.

[4]. TABSH S W, ABDELFATAH AS. Influence of Recycled Concrete Aggregates on Strength Properties of Concrete [J].Construction and Building Materials, 2009, 23(2):1163-1167

[5]. IKEDA T, YAMANE S. Strengths of Concrete Containing Recycled Aggregate[C]//KASAI Y. Proceedings of the Second International RILEM Symposium on Demolition and Reuse of Concrete and Masonry-Tokyo: CRC Press, 1988:585-594

[6]. RAVINDRARAJAH R S, TAM C T. Recycled Concrete as Fine and Coarse Aggregates in Concrete [J]. Magazine of Concrete Research, 1987, 39(141):214-220

[7]. SAGOE-CRENTSIL K, BROWN T, TAYLOR AH. Performance of Concrete Made with Commercially Produced Coarse Recycled Concrete Aggregate [J].Cement and Concrete Research, 2001.31(5):707-712

[8]. GUPTA S M. Strength Characteristics of Concrete Made with Demolition Waste as Coarse Aggregate[C]// Phoenix Pub House. Proceedings of the International Conference on Recent Development in Structure Engineering, New Delhi: Phoenix Pub House, 2001:364-373.

[9]. XIAO jian-zhuang, LI jia-bin, SUN Zhen-ping, et al. Study on Compressive Strength of Recycled Aggregate Concrete [J].Journal of Tongji University: Natural Science, 2004, 32(12):1558-1561.

[10]. LI Xu-ping. Study on Mechanical Properties of Recycled Aggregate Concrete (I)-Behaviour under Uniaxial Compression [J].Journal of Building Materials, 2007, 10(5):598-603.

[11]. ZHANG Xue-bing, DENG Shou-chang, DENG Xu-hua, et al. Experimental Research on a Few Main Factors Influencing Strength of the Recycled Concrete [J]. Natural Science Journal of Xiangtan University, 2005, 27(1)129-133.

[12]. MONTGOMERY D G. Workability and Compressive Strength Properties of Concrete Containing Recycled Concrete Aggregate[C]// University of Wollongong. Sustainable Construction: Use of Recycled Concrete Aggregate. Wollongong: University of Wollongong, 1998:287-296.

[13]. HE De-zhan. Japanese Concrete Strengthening Treatment Technology [J].Special Structures, 2000, 17(3):39.

[14]. BRU K, TOUZE S, BOURGEOIS F, et al. Assessment of a Microwave-assisted Recycling Process for the Recovery of High-quality Aggregates from Concrete Waste[J].International Journal of Mineral Processing, 2014, 126:90-98.

[15]. TATEYASHIKI H, SHIMA H, MATSUMOTO Y, et al. Properties of Concrete with High Quality Recycled Aggregate by Heat and Rubbing Method[J].Proceedings of JCI,2001,23(2):6166. 
[16]. MA Xin-wei, HAN Zhao-xiang, LI Xue-ying, et al. Thermal Treatment of Waste Concrete and the Rehydration Properties of the Dehydrated Cement Paste[J]. Journal of Qingdao Technological University, 2009, 30(4):93-97.

[17]. LI Qiu-yi, LI Yun-xia, ZHU Chong-ji. The influence of a particle shape correcting technique in properties of recycled coarse aggregate [J].MATERIALS SCIENCE \& TECHNOLOGY, 2005, 13(6): 579-585.

[18]. ZHU Ya-guang, HAN Ji-quan, Li Qiu-yi, et al. Experimental Research on the Influence by Particle Shaping on Mechanical Performance of Recycled Aggregate Concrete[J].Journal of Qingdao Technological University,2009,30(4):115-118.

[19]. ZHU Chong-ji, LI Qiu-yi, LI Yun-xia.The Affection by Aggregate-shaping on Durability of the Recycled Aggregate Concrete[J].China Building Materials Science \& Technology, 2007, 16(3):6-10.

[20]. RYU J S. Improvement on Strength and Impermeability of Recycled Concrete Made from Crushed Concrete Coarse Aggregate [J]. Journal of Materials Science Letters, 2002, 21 (20): 1565-1567.

[21]. SUN Cheng-cheng, YUAN Dong, SONG Jian-xue. Study on Effect of Compressive Strength of Recycled Aggregate Concrete with Secondary Mixing Process [J].Concrete, 2008(6):125-128.

[22]. TAM V W Y,GAO X F,TAM C M. Microstructural Analysis of Recycled Aggregate Concrete Produced from Two-stage Mixing Approach[J].Cement and Concrete Research ,2005.35(6):1195-1203.

[23]. TAMUBA H,NISHIO A,OHASHI J, et al. High Quality Recycled Aggregate Concrete(HIRAC)Processed by Decompression and Rapid Release[C]//American Concrete Institude.Proceedings of Fifth CANMET/ACI International Conference on Recent Advances Concrete Institute,2001:491-502.

[24]. ZHAO Wu, FENG Zhou-xu. Research on the Strengthening Mechanism of Vibration Mixing of Recycled Concrete [J].Concrete, 2006(8):17-20.

[25]. KONG De-yu, WU Xian-jun, WEI Su. Research on Recycled Aggregate Concrete [J].Journal of Zhejiang University of Technology, 2003,31(1):28-32.

[26]. JUNGMANN A. Building Rubble Treatment Using the Alljig in Europe and USA [J].Aufbereitungs-technik, 1997, 38(10):543-549.

[27]. KATZ A. Properties of Concrete Made with Recycled Aggregate from Partially Hydrated Old Concrete [J].Cement and Concrete Research, 2003, 33(5):703-711.

[28]. KOUSC, POONCS. Properties of Concrete Prepared with PVA-impregnated Recycled Concrete Aggregates [J].Cement and Concrete Composites, 2010, 32(8):649-654.

[29]. CHEN Jian-liang, NI Zhu-ping. Strengthening Treatment to Improve the Performance of Recycled Aggregate Concrete [J]. Low Temperature Architecture Technology, 2011, 33(2):1416.

[30]. YANG Ning, WANG Chong-ge, ZHAO Mei-xia. Research on Intensifying Technique of Recycled Aggregate [J].New Building Materials, 2011, 38(3):45-47.

[31]. ABBASA, FATHIFAZLG, POURNIERB, et al. Quantification of the Residual Mortar Content in Recycled Concrete Aggregates by Image Analysis[J].Materials Characterization,2009,60(7):716-728. 
[32]. FAN Xiao-ping, XU Yin-fang. Strengthening Test of Recycled Aggregate [J]. Shanghai Building Materials, 2005(4):22-23.

[33]. DU Ting, Li Hui-qiang, WU Xian-guo. Experimental Study on Strengthening Concrete Recycled Aggregate [J].New Building Materials, 2002, 29(3)6-8

[34]. KATZA. Treatments for the Improvement of Recycled Aggregate [J].Journal of Materials in Civil Engineering, 2004, 16(6):597-603.

[35]. WANG Zi-ming, PEI Xue-dong, WANG Zhi-yuan. Improving the Strength of Mornar with Polymer Emulsion for the Waste Concrete Aggregate [J]. Concrete, 1999(2):44-47.

[36]. Shi-Cong Kou, Chi-Sun Poon. Properties of Concrete Prepared with PVA-impregnated Recycled Concrete Aggregates [J].Cement and Concrete Composites, 2010, 32(8):649-654.

[37]. SPAETHV, TEGGUERAD. Improvement of Recycled Concrete Aggregate Properties by Polymer Treatments [J].International Journal of Sustainable Built Environment, 2013, 2(2):143152.

[38]. TSUJINOM, NOGUCHIT, TAMURAM, et al. Application of Conventionally Recycled Coarse Aggregate to Concrete Structure by Surface Modification Treatment[J].Journal of Advanced Concrete Techology,2007,(5):13-25.

[39]. GRABIECAM, KLAMAJ, ZAWALD, et al. Modification of Recycled Concrete Aggregate by Calcium Carbonate Bio-deposition [J].Construction and Building Materials,2012,34:145-150.

[40]. ZHANGJ, SHIC, LI Y et al. Performance Enhancement of Recycled Concrete Aggregates through Carbonation [J].Journal of Materials in Civil Engineering, 2015, 27(11):1-6.

[41]. CUI Zheng-long, TONG Hua-bin, WU Xiang-yu, et al. Research on Autoclave Curing Effect of the Mechanical Properties of Recycled Aggregate Concrete [J].Bulletin of the Chinese Ceramic Society, 2014, 33(3):596-599.

[42]. AKBARNEZHADA, ONGKCG, ZHANGMH et al. Microwave-assisted Beneficiation of Recycled Concrete Aggregates[J].Construction of Building Materials, 2011,25(8):3469-3479.

[43]. XIAO Jian-zhuang, WU Lei, FAN Yu-hui. Test on Modification of Recycled Coarse Aggregate by Microwave Heating [J]. Concrete, 2012(7):55-57.

[44]. DAI Jun, WANG Qian. Preliminary Studies on New Beneficiation Technique of Recycled Concrete Aggregate [J].Concrete, 2014(8):133-135. 